\title{
Human Papillomavirus-63
}

National Cancer Institute

\section{Source}

National Cancer Institute. Human Papillomavirus-63. NCI Thesaurus. Code C156054.

A virus comprised of a protein coat (capsid) surrounding a circular, double-stranded DNA organized into coding and non-coding regions, which can induce epithelial lesions.

Infection with human papillomavirus-63 may be associated with a risk for cervical cancer. 